\title{
APLIKASI MAKE UP FLAWLESS DAN MODEL HIJAB DALAM
}

\section{AKTIVITAS SEHARI-HARI}

\author{
${ }^{(1)}$ Fitria Wahyuningtyas, ${ }^{(2)}$ Dyah Ayu Utami, ${ }^{(3)}$ Meidya Tri Wahyuningdyah, ${ }^{(4)}$ Agus Ridwan \\ ${ }^{(1)}$ Fakultas Keguruan Ilmu Pendidikan, ${ }^{(2)}$ Fakultas Matematika dan Ilmu Pengetahuan Alam, ${ }^{(3)}$ Fakultas \\ Ekonomi ${ }^{(4)}$ Dosen Pendidikan Kesejahteraan Keluarga Fakultas Keguruan Ilmu Pendidikan \\ ${ }_{(1,2,3,4)}$ Universitas PGRI Adi Buana Surabaya \\ Email: ${ }^{(4)}$ agus.ridwan@unipasby.ac.id
}

\begin{abstract}
ABSTRAK
Program workshop dan kompetisi gaya modis adalah kontes make up dan hijab. Dimana program diadakan dengan maksud untuk memberikan pengetahuan bagi warga desa pugeran dalam aplikasi rias wajah yang sempurna untuk kebutuhan sehari-hari. Make up sempurna adalah riasan sempurna yang sangat halus. Metode pelaksanaan yang dilakukan dalam kegiatan ini adalah mensosialisasikan kepada warga masing-masing dusun setelah itu diikuti dengan workshop dan gaya lombah yang modis.
\end{abstract}

Kata kunci: Make up, Hijab, gaya modis

\section{ABSTRACT}

Workshop program and fashionable style competition is a make up and hijab contest. Where the program is held with the intent to provide knowledge for pugeran villagers in the application of flawless make up properly for daily needs. Flawless make up is a perfect makeup that is perfectly smooth. The method of implementation carried out in this activity is to socialize to the residents of each hamlet after that followed by workshop and lombah fashionable style.

Keywords: Make up, Hijab, fashionable style

\section{PENDAHULUAN}

Kuliah kerja nyata pembelajaran
pemberdayaan masyarakat (KKN-PPM)
merupakan suatu kegiatan untuk wajib
dilaksanakan yang memadukan pelaksanaan
Tri Dharma Perguruan Tinggi dengan
metode pemberian pengalaman belajar dan
bekerja kepada mahasiswa, dalam kegiatan
pemberdayaan masyarakat. Dalam kegiatan
KKN-PPM ini Universitas PGRI Adi Buana
Surabaya melakukan pembagian seluruh
mahasiswa angkatan 2014. Pada tugas ini
kami mendapatkan tempat bertugas di
kecamatan Gondang Mojokerto, tepatnya di
desa Pugeran. Dari satu kelompok yang
terdiri dari 44 orang, kami dibagi menjadi
beberapa kelompok lagi dimana pembagian
kelompok ini dilakukan untuk menjalankan
beberapa program yang harus dilaksanakan
dalam kegiatan KKN-PPM ini. Maka dari
itu, kami mengadakan program workshop

dan lomba fashionable style di desa Pugeran. Dimana program tersebut diadakan dengan maksud untuk memberikan pengetahuan untuk warga desa pugeran dalam pengaplikasian make up flawless dengan benar untuk kebutuhan sehari-hari. Make up flawless merupakan make up yang sempurnadan mulus tanpa noda. Selain itu, pada program ini terdapat lomba hasil make up flawless dan hijab dimana lomba ini dimaksudkan untuk memotivasi beserta menumbuhkan kreativitas dari warga desa pugeran dalam berhijab. 


\section{METODE PELAKSANAAN}

Kegiatan ini dilaksanakan di balai desa Pugeran kec. Gondang kab. Mojokerto. Kegiatan ini dilaksanakan pada Sabtu, 10 Februuari 2018. Sasaran dari kegiatan ini adalah ibu PKK Desa Pugeran. Metode pelaksanaan pada acara ini adalah dengan workshop terlebih dahulu mengenai pengertian make up flawless dan tutorialnya setelah itu tutorial hijab dan dilanjutkan dengan lomba fashion show untuk para model peserta. Pada kegiatan ini bekerja sama dengan ibu PKK desa pugeran. Dimana kegiatan ini berlangsung dengan mengambil empat orang perwakilan dari setiap dusun di desa Pugeran. Berikut adalah dokumentasi pada saat kegiatan berlangsung :

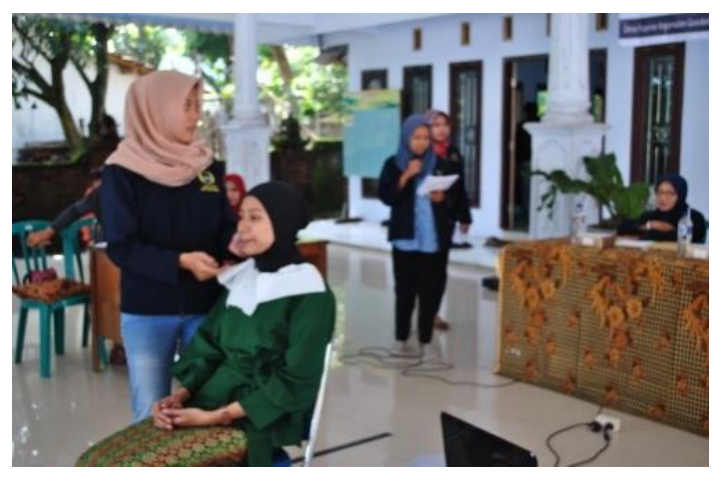

Gambar 1. Penyampaian materi beserta praktek make up

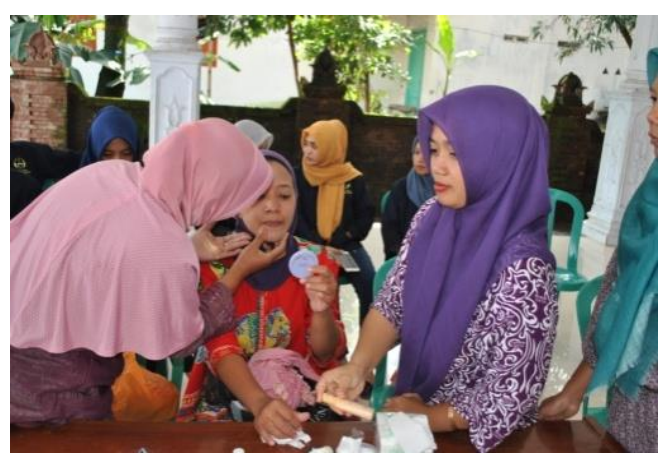

Gambar 2. Peserta mempraktek kan pada masing-masing modelnya

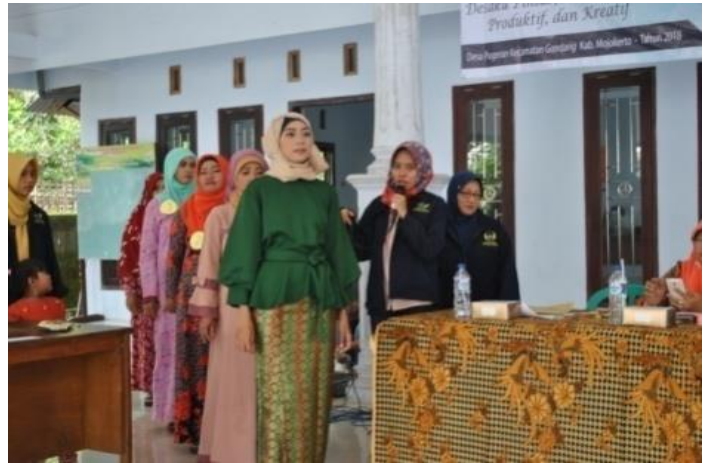

Gambar 3. Para model lomba fashion show

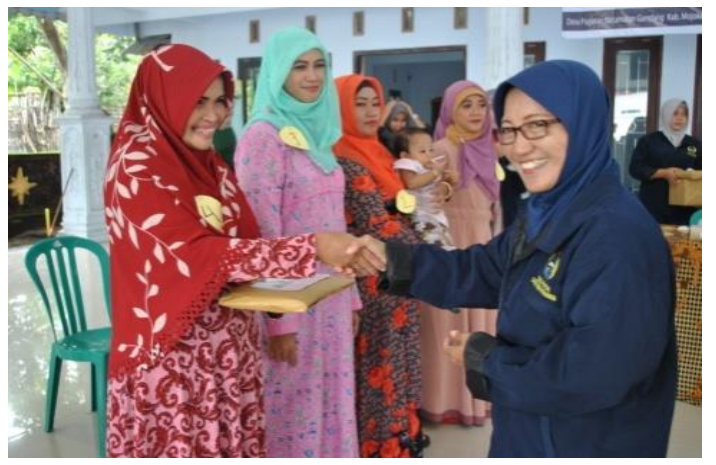

Gambar 4. Penyerahan hadiah

\section{HASIL DAN PEMBAHASAN}

Hasil dari program kegiatan fashionable style ini dilakukan pada tanggal 10 Februari 2018. Target peserta workshop adalah 16 peserta. Sumber dana yang digunakan dalam menjalankan program ini berasal dari LPPM dan iuran mahasiswa KKN 2018.

Adapun rincian jadwal program kegiatan ini adalah :

a) Sosialisasi

Bersosialisasi kepada masingmasing dusun untuk memberikan pemberitahuan bahwa akan diadakan program workshop dan fashionable style. Sosialisasi dilaksanakan pada tanggal 9 Februari 2018

b) Persiapan

Persiapan dilakukan sebelum acara dimulai pada 06.00-07.00. 
c) Pembukaan

Pembukaan acara dilakukan pada 09.00-09.15 oleh saudari Nanda Putri Ashmita.

d) Sambutan dari koordinator desa Sambutan dari saudara Rendi Sudrajat selaku koordinator desa pada 09.15-09.30.

e) Penyampaian materi Penyampaian materi oleh saudari Ayang Pawita disertai mengaplikasikan make up dan tutorial hijab pada model pada 09.30-10.15.

f) Pemraktekan make up oleh peserta pada model.

Para peserta mempraktekkan make up pada model beserta pada 10.00-11.00.

g) Penilaian hasil make up

Penilaian dilakukan oleh tiga juri pada 11.00-11.15.

h) Lomba atau penampilan fashion show.

Semua model masing-masing regu per dusun menampilkan hasil make up dan hijab pada 11.15-11.30.

i) Penentuan juara

Juri menentukan juara I-juara IV dengan beberapa kreteria penilaian. Penilaian dilakukan pada 11.30-11.45.

j) Penutup

Penutup pada 11.45 .

\section{KESIMPULAN}

Senantiasa tampil cantik dan memesosana selalu menjadi impian dan harapan banyak wanita, mengingat sudah menjafi kodrat wanita untuk selalu ingin berdandan dan berhias. Terkadang, muncul keinginan agar tampil cantik setiap hari tanpa perlu repot-repot berhias atau merawat diri. Sebagian wanita beranggapan bahwa ia tidak cukup percaya diri jika kalah cantik dari wanita lain atau tampil' seadanya'didepan orang lain.

Demi hasil cantik yang cepat itulah banyak wanita yang rela membelanjakan uang untuk memenuhi harapannya menjadi wanita cantik dan sempurna. Setiap wanita diperbolehkan untuk tampil cantik dan menawan. Namun, alangkah baiknya jika tetap menyesuaikan dengan kebutuhan. Makeup yang natural lebih diminati para wanita untuk tampil menarik saat berakhtifitas sehari-hari. Make up natural dan flawless yang cocok untuk sehari-hari. Memeberikan beberapa tips untuk membuat riasan simple dan natural. Salah satunya dengan tidak terlalu bermain menggunakan warna-warna gelap ketika diterapkan disiang hari. Tak lupa tetap menutupi kekurangan wajah menggunakan makeup.

Menutupi kekurangan wajah seperti jeraeat, bekas luka, dan kantung mata bisa pakai concealer. Selain itu, bentuk hidung juga perlu menggunakan shading dan highlighter agar terlihat lebih mancung. Akan tetapi hati-hati saat menggunakan shading atau contoring terutama pada bagian pipi. Mengapa? Shading yang terlalu grlap bisa membuat wajah terlihat lebih tua.

Blush on juga perlu diperhatikan pemakaiannya. Sesuaikan blus on dengan warna kulit. Untuk menciptakan kulit yang segar di siang hari, blush on pink bisa menjadi pilihan jika kulit cenderung putih. Bila warna kulit cokelat atau grlap bisa menggunakan blus on berwarna orange.

Untuk eyeshadow pilih warna yang natural seperti coklat dan pink muda. Sedangkan untukmemilih lipstik juga diperhatikan sesuai warna kulit. Memilih lipstik yang cocok dengan warna kulit memang gampang-gampang susah. Sangat penting memilih warna lipstik yang sesuai dengan warna kulit jika ingin mrndapatkan tampulan yang lebih maksimal. Tidak semua warna lipstik yang memikat dapat sesuai jika dipoles di bibir kita. Tentu kita tidak mau kelihatan norak karena warna lipstik yang 'bertabrakan' dengan warna kulit.

$$
\text { Biasanya wanita sering }
$$
mencocokkan warna lipstik dengan warna busana yang fipakai. Memang tidak salah, tapi sebaiknya akan lebih baik jika menyesuaikan dengan warna kulit wajah. Berikut ini contoh warna lipstik yang sesuai dengan warna kulit. 
Jenis kulit putih warna lipstik yang cocok adalah warna-warna lembut seperti: pink cream,peach, plum reds, berry, wine reds, brown, light medium brown dan beighe. Warna lipstik yang dihindari adalah warna-warna terang seperti: fuchia, merah, dan orange karena membuat kulit tampak makin pucat.

Jenis kulit langsat warna lipstik yang cocok adalah warna-warna hangat seperti: merah marun, orange bata, mera kecokelatan, dan merah keunguan, deep brown, dark berry. Warna lipstik yang hendaknya dihindari adalah warna nude yang membuat kulit tampak lebih kusam, serta warna orange dan pink cerah yang memberikan efek gelap pada kulit.

Jenis kulit sawo matang warna lipstik yang cocok adalah gradasi warna kecokelatan, seperti: cokelat kemerahan, beige, dan coklat tua, caramel, medium brown dan creamy coffe dan segala jenis warna coklat yang dapat membuat wajah terlihat lebih segar. Warna lipstik yang harus dihindari : warna yang mengandung unsur merah, orange, dan pink yang membuat kulit tampak lebih gelap. Hindari pemakaian shimmering yang justru akan memberikan efek terlalu tebal dan terlalu tegas pada bibir.

Jenis kulit hitam warna lipstik yang cocok adalah warna cokelat muda, pink nude, dan warna-warna netral lain, palet merah, coffe brown, dark brown dan warna gelap lainnya akan memberikab kesab anggun dan tegas pada kulit. Warna lipstik yang dihindari adalah warna cerah seperti orange, pink dan nerah karena terlalu kontras dengan warna kulit.

Dari pelaksanaan program tersebut dapat membantu memberikan pengetahuan tentang bagaimana cara yang harus dilakukan agar make up dapat terlihat cantik dan natural. Selain itu dapat menambah pengetahuan tentang bagaimana cara berhijab yang simpel namun terlihat menarik.

\section{REFERENSI}

Http://m.balikpapan.prokal.co/read/news/140 283-apa-sih-make-up-flawless-ity

Http://lppm.usu.ac.id/index.php/progamkerja/kkn-ppm
Utami, nunik. 2008. Menjadi Secantik Aisyah. Jakarta: Gen Mirqat.

Nuha Muklatul Arwah, Raisa. 2012. Awet Muda Tetap Cantik\& Sehat Alami. Yogyakarta: Leutika. 